\title{
Ablation of beta subunit of protein kinase CK2 in mouse oocytes causes follicle atresia and premature ovarian failure
}

\author{
Qiu-Xia Liang 1,2, Zhen-Bo Wang ${ }^{2,3}$, Fei Lin ${ }^{2,4}$, Chun-Hui Zhang ${ }^{1}$, Hong-Mei Sun ', Liang Zhou', Qian Zhou', \\ Heide Schatten ${ }^{5}$, Filhol-Cochet Odile ${ }^{6}$, Boldyreff Brigitte', Qing-Yuan Sun ${ }^{2,3}$ and Wei-Ping Qian'
}

\begin{abstract}
Premature ovarian failure (POF), a major cause of female infertility, is a complex disorder, but the molecular mechanisms underlying the disorder are only poorly understood. Here we report that protein kinase CK2 contributes to maintaining follicular survival through PI3K/AKT pathway and DNA damage response pathway. Targeted deletion of CK2 $\beta$ in mouse oocytes from the primordial follicle stage resulted in female infertility, which was attributed to POF incurring by massive follicle atresia. Downregulated PI3K AKT signaling was found after CK2 $\beta$ deletion, indicated by reduced level of phosphorylated AKT (S473, T308, and S129) and altered AKT targets related to cell survival. Further studies discovered that CK2 $\beta$-deficient oocytes showed enhanced $\gamma \mathrm{H} 2 \mathrm{AX}$ signals, indicative of accumulative unrepaired DSBs, which activated CHK2-dependant p53 and p63 signaling. The suppressed PI3K/AKT signaling and failed DNA damage response signaling probably contribute to large-scale oocyte loss and eventually POF. Our findings provide important new clues for elucidating the mechanisms underlying follicle atresia and POF.
\end{abstract}

\section{Introduction}

Premature ovarian failure (POF) refers to amenorrhea in women of less than 40 years of age accompanied by elevated menopausal levels of serum gonadotropins (folliclestimulating hormone, $\mathrm{FSH}>40 \mathrm{IU} / \mathrm{l}$ ) and decreased estrogen ${ }^{1}$. POF is an ovarian dysfunction characterized by premature depletion of ovarian follicles in $\sim 1 \%$ of women under the age of 40 years and $0.1 \%$ under the age of 30 years $^{2}$, which usually leads to female infertility. The causes of POF vary and are complex, and it includes genetic aberrations $^{3-5}$, autoimmune ovarian damage $\mathrm{e}^{6,7}$, therapeutic interventions such as radiotherapy ${ }^{8}$ and

\footnotetext{
Correspondence: Q-Y. Sun (sunqy@ioz.ac.cn) or W-P. Qian (qianweipingsz@126. com)

${ }^{1}$ Department of Reproductive Medicine, Peking University Shenzhen Hospital, 518036 Shenzhen, Guangdong, China

${ }^{2}$ State Key Laboratory of Stem Cell and Reproductive Biology, Institute of Zoology, Chinese Academy of Sciences, 100101 Beijing, China

Full list of author information is available at the end of the article These authors contributed equally: Qiu-Xia Liang, Zhen-Bo Wang, Fei Lin. Edited by P. Agostini
}

chemotherapy ${ }^{9}$, with genetic factors being the main causes. Accumulating genes in the $\mathrm{X}$ chromosome such as FMR $1^{4,10}, F M R 2^{11}, B M P 15^{12-14}$ and genes in the autosome such as FOXL2 $2^{15,16}, \mathrm{FSHR}^{17}$, LH receptor ${ }^{18}$, and inhibin $\mathrm{A}^{19,20}$ are known to be involved in POF; however, for many years, the underlying mechanisms of POF have largely remained unknown.

Protein kinase CK2 is a ubiquitous serine/threonine protein kinase that is a heterotetramer consisting of two regulatory subunits, CK2 $\beta$, and two catalytic subunits, CK $2 \alpha$ and CK $2 \alpha^{21}$. Depending on specific functions, the catalytic and regulatory subunits may exist in the forms of $\alpha 2 \beta 2, \alpha^{\prime} 2 \beta 2, \alpha \alpha^{\prime} \beta 2$, or unassembled molecules ${ }^{22,23}$. CK2 displays functions in numerous cellular processes by participating in multiple signaling pathways, including PI3K/AKT ${ }^{24-27}$, Wnt/ $\beta$-catenin ${ }^{28-31}$, and the DNA damage response pathway ${ }^{32-36}$. Extensive studies have shown that CK2 is involved in the promotion of cell survival and anti-apoptotic functions in normal and

\section{(c) The Author(s) 2018}

(c) (i) Open Access This article is licensed under a Creative Commons Attribution 4.0 International License, which permits use, sharing, adaptation, distribution and reproduction in any medium or format, as long as you give appropriate credit to the original author(s) and the source, provide a link to the Creative Commons license, and indicate if changes were made. The images or other third party material in this article are included in the article's Creative Commons license, unless indicated otherwise in a credit line to the material. If material is not included in the article's Creative Commons license and your intended use is not permitted by statutory regulation or exceeds the permitted use, you will need to obtain permission directly from the copyright holder. To view a copy of this license, visit http://creativecommons.org/licenses/by/4.0/. 


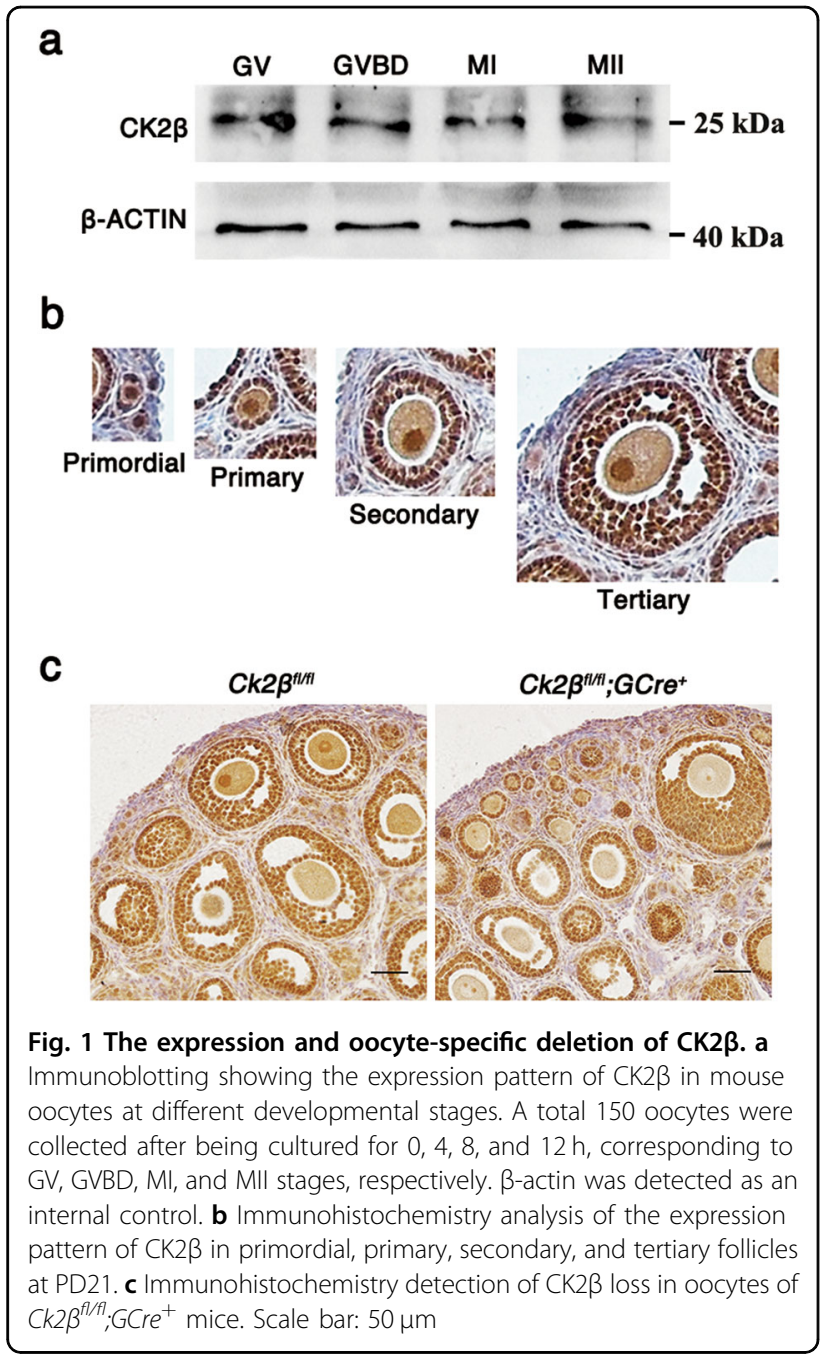

cancer cells. In HEK-293T cells, CK2 phosphorylates AKT/PKB at Ser129, preventing AKT Thr308 dephosphorylation and enhancing the catalytic activity of AKT/ $\mathrm{PKB}^{24,30,37}$, which in turn phosphorylates $\beta$-catenin at Ser552 and promotes its nuclear localization, eventually strengthening resistance to apoptosis by upregulating anti-apoptotic survivin gene transcription ${ }^{30}$. CK2 regulates PI3K signaling by phosphorylating PTEN $\mathrm{C}$ terminus ${ }^{38,39}$, which enhances the stability and inhibits the activity of PTEN ${ }^{38-40}$. In leukemia cells, CK2 inhibits Ikaros, a tumor suppressor, which can repress the transcription of genes promoting the PI3K pathway ${ }^{27}$. Since CK2 was first reported to facilitate DNA single-strand breaks repair $^{33}$, accumulating evidence has shown that CK2 is involved in DNA damage repair pathway. CK2 regulates the G1/S DNA damage checkpoint by targeting p53 $3^{41,42}$, p53 regulatory proteins (e.g., MDM-2) ${ }^{43,44}$ and Cdk-inhibitory proteins such as p21 ${ }^{\mathrm{WAF} 1 / \mathrm{CIP} 1} 45,46$ and p27 ${ }^{\mathrm{KIP} 1} 47$. CK2 also contributes to the G2/M damage checkpoint by targeting or interacting with proteins such as $\mathrm{CHK} 1^{22}, \mathrm{CHK} 2^{48}$ and BRCA $1^{49}$. Generally, CK2 functions as a monitoring hub of the cell cycle and apoptosis, integrating diverse signals into the appropriate cellular responses.

$C K 2 \alpha^{-/-}$embryos die in mid-gestation, with defects in heart and neural tube ${ }^{50}$. CK2 $2 \alpha^{-1-}$ females show normal fertility, but males are infertile. Male mice lacking CK2 $\alpha$ ' show extensive germ cell apoptosis characterized by nuclear abnormalities ranging from spermatogonia to early spermatids ${ }^{51,52}$. CK2 $2 \beta^{-1-}$ mice die shortly after implantation with no signs of apoptosis but reduced cell proliferation. $C K 2 \beta^{-1-}$ blastocysts cannot develop an inner cell mass in vitro ${ }^{53}$. Zygote-specific knockout of $C K 2 \beta$ is destructive for embryonic stem cells and primary embryonic fibroblasts ${ }^{53}$. The above studies demonstrate that CK2 $\beta$ is indispensable for cell survival. However, the roles of CK $2 \beta$ in folliculogenesis/oogenesis are largely unknown. Here we targeted CK2 $\beta$ for deletion in oocytes from the primordial follicle stage by crossing $C k 2 \beta^{f l / f l}$ mice with Gdf9-Cre mice. We found that CK2 $\beta$ was essential for female fertility and loss of CK2 $\beta$ caused ovarian follicle atresia and POF.

\section{Results}

\section{Oocyte-specific deletion of $C k 2 \beta$ gene causes mice infertility}

Toward determining the potential roles of CK2 $\beta$ in the female reproductive system, expression patterns of CK2 $\beta$ in ovaries and oocytes at different developmental stages were assessed through immunoblotting and immunohistochemistry. Immunoblotting revealed that CK2 $\beta$ was stably and highly expressed in GV, GVBD, MI, and MII oocytes (Fig. 1a). Within the ovary, immunohistochemistry revealed that CK2 $\beta$ located in the nuclei of oocytes and granulosa cells from primordial follicles to antral follicles (Fig. 1b). These data suggest that CK2 $\beta$ potentially functions in folliculogenesis/oogenesis.

To confirm our hypothesis, we generated oocytespecific $C K 2 \beta$ mutant mice by crossing $C k 2 \beta^{f l}$ mice in which exon I-II were targeted with transgenic mice expressing Gdf9 promotor-driven Cre recombinase (Supplementary Figure1). In Gdf9-Cre mice, Cre was expressed from primordial to later follicular stages. Histological analysis of $C k^{2} \beta^{f l / f l} ; G C r e^{+}$mouse ovaries showed loss of CK2 $\beta$ localization in nuclei of oocytes, indicating functional deletion of CK2 $\beta$ (Fig. 1c).

To observe the effect of oocyte-specific deletion of CK2 $\beta$ on fertility, a breeding assay was conducted by mating $C k 2 \beta^{f l / f l}$ or $C k 2 \beta^{f l f l} ; G C r e^{+}$female mice with wildtype males of tested fertility for 6 months. Continuous breeding assessment indicated that $C k 2 \beta^{f l / f l} ; G C r e^{+}$ females were completely infertile (Fig. 2a). 

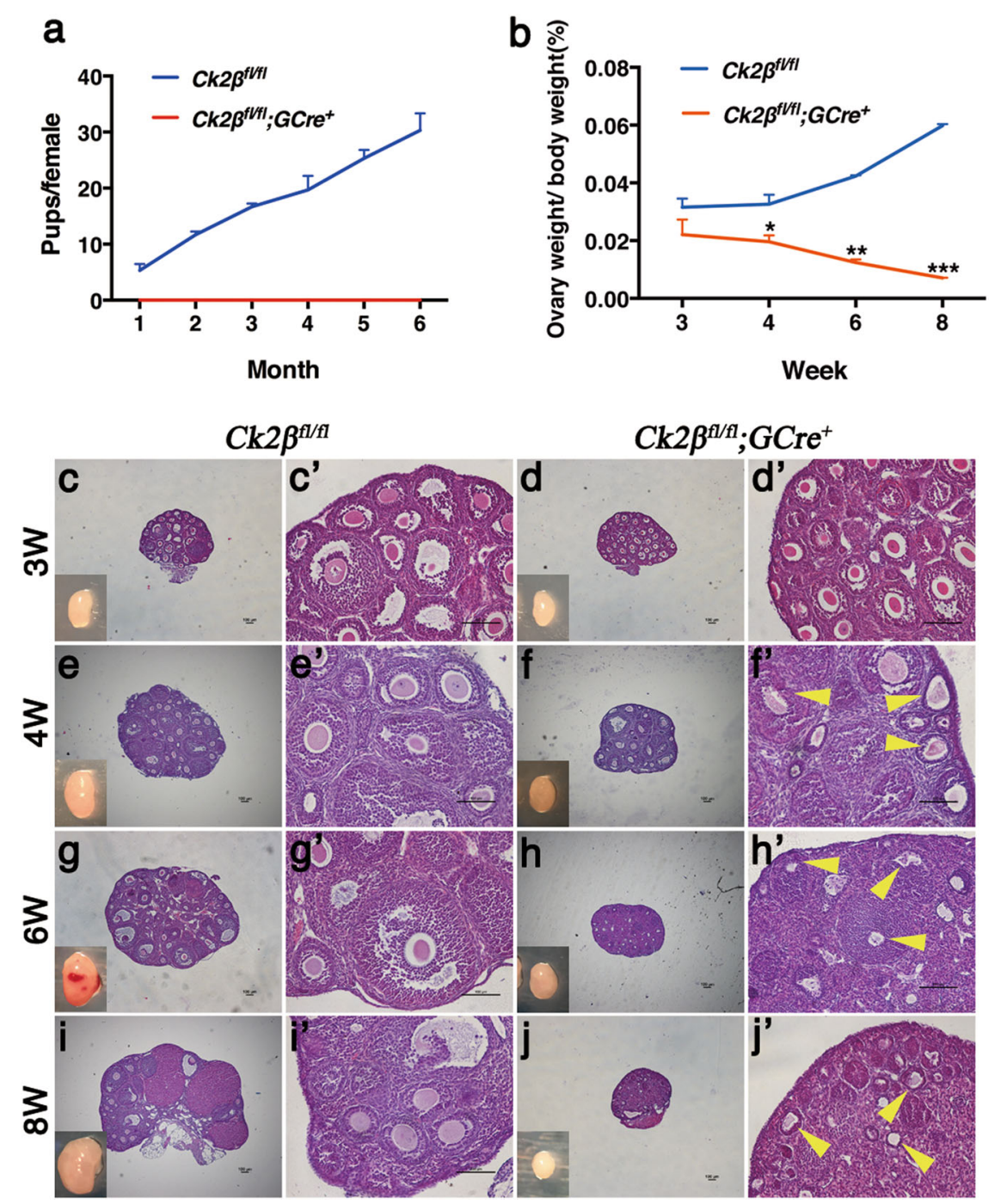

Fig. 2 Infertility and follicle atresia in $C \mathbf{k}_{2} \beta^{f / f} ; G C r e^{+}$mice. a Comparison of the accumulative number of pups per $C k 2 \beta^{f / f l}$ female and $C k 2 \beta^{f / f}$; $\mathrm{GCre}^{+}$female for 6 months. At least five mice of each genotype were used in this assay. $\mathbf{b}$ Ovary weight to body weight ratio of $C k 2 \beta^{f / / f}$ and $C k 2 \beta^{f l / f}$; $\mathrm{GCre}^{+}$mice at 3, 4, 6, and 8 weeks of age after birth. For each time point, at least three mice of each genotype were used for analysis. Data are presented as the mean \pm SEM. $\left.P<0.05^{(*)}, 0.011^{* *}\right)$ or $\left.0.001^{(* *}\right)$. c-j Representative ovarian histology of $C k 2 \beta^{f / f l}$ and $C k 2 \beta^{f / f l} ; G C r e^{+}$mice of $3,4,6$, and 8 weeks of age, respectively. Images $\mathbf{c}^{\prime}-\mathbf{j} \mathbf{j}^{\prime}$ correspond to the partial magnification of images $\mathbf{c}-\mathbf{j}$. Yellow arrowheads in $\mathbf{f}^{\prime}, \mathbf{h}^{\prime}$, and $\mathbf{j}^{\prime}$ indicate atretic follicles. For each time point, at least three mice of each genotype were used for analysis. Scale bar: $100 \mu \mathrm{m}$

\section{Ablation of $C k 2 \beta$ gene expression in oocytes at the} primordial follicle stage results in follicle atresia and POF

To determine whether the infertility was due to ovarian dysfunction and consequential functional oocyte loss, we first measured the size of ovaries from $C k 2 \beta^{f l / f l}$ and $C k 2 \beta^{f l}$ ${ }^{f l}$; $\mathrm{GCre}^{+}$mice. As shown in Fig. 2b, the size of the ovaries of $C k 2 \beta^{f l / f l}$ mice continued to increase from week 3 to week 8 , with a mean ovarian weight ratio of $0.0316 \%$, $0.0326 \%, 0.0424 \%$, and $0.0598 \%$ corresponding to week 3 , 4,6 , and 8 , respectively. Compared to the control, the ovary size of $\mathrm{Ck}_{2} \beta^{f l f l}$; $\mathrm{GCre} \mathrm{C}^{+}$mice decreased slightly in week 3 and decreased sharply from week 4 to week 8 , with mean ovarian weight ratio of only $0.0221 \%, 0.0196 \%$,
$0.0124 \%$, and $0.0071 \%$. These data revealed that CK2 $\beta$ deletion resulted in atrophy of ovaries in mice.

To clarify the cause of ovarian atrophy, we next examined the morphology of ovaries from both $C k 2 \beta^{f l / f l}$ and $C k 2 \beta^{f l / f l} ; \mathrm{GCr}^{+}$mice. At 3 weeks of age, histological assessment revealed that $C k 2 \beta^{f l / f l}$ mice showed normal ovarian morphology characterized by the presence of primordial and activated follicles including primary, secondary, and antral follicles (Fig. 2c, c'). All of these structures were also found in the $C k 2 \beta^{f l / f l} ; G C r e^{+}$mouse ovaries. Although a few follicles underwent atresia, the ovaries looked healthy on the whole (Fig. 2d, d'). At 4 weeks of age, all types of follicles could be found in both 
$C k 2 \beta^{f l / f l}$ mice (Fig. 2e, e') and $C k 2 \beta^{f l / f l} ; G C r e^{+}$mice (Fig. 2f, $\left.\mathrm{f}^{\prime}\right)$. However, most follicles in the ovaries of $C k 2 \beta^{f l f f}$; $\mathrm{GCre}^{+}$mice showed signs of atresia (Fig. 2f', yellow arrows) in contrast to control ovaries that contained substantial healthy-looking follicles (Fig. 2e'). At 6 weeks, the time of sexual maturity, massive atretic follicles (Fig. 2h', yellow arrows) appeared in the ovaries of $C k 2 \beta^{f l}$ ${ }^{f l}$;GCre ${ }^{+}$mice (Fig. 2h, h') compared to $C k 2 \beta^{f l / f l}$ mice (Fig. 2g, g'). Although most atretic follicles maintained follicular structures, the oocytes in atretic follicles were eliminated and the space was filled with granulosa cells (Fig. 2h, h'). By 8 weeks of age, in contrast to $C k 2 \beta^{f l / f l}$ ovaries (Fig. 2I, i'), almost all types of follicles had been depleted in $C k 2 \beta^{f l / f l}$; $G C r e^{+}$ovaries, and it was difficult to find follicular structures in the ovaries of $C k 2 \beta^{f l f f} ; G C r e^{+}$ mice (Fig. 2j, j').

Quantitative analysis revealed that the numbers of primary, secondary, and antral follicles in the ovaries of $C k 2 \beta^{f l f l}$; $\mathrm{GCre}^{+}$mice were similar to those of $C k 2 \beta^{f l f l}$ mice at 3 and 4 weeks, but the number of primordial follicles within the ovaries of $C k 2 \beta^{f l f l f} ; G C r e^{+}$mice was markedly reduced as compared to $C k 2 \beta^{f l f l}$ mice (Fig. 3a, b). At 6 weeks, in addition to primordial follicles, significant differences were also observed in the secondary and antral follicles (Fig. 3c). By 8 weeks of age, all types of follicles in ovaries of $C k 2 \beta^{f l / f l}$; $\mathrm{GCre}^{+}$mice were significantly decreased (Fig. 3d). In general, the primordial follicles reduction occurred at 3 weeks of age and continued decreasing until depletion of the primordial follicle pool at young adulthood (8 weeks) in $C k 2 \beta^{f l f f l} ; G C r e^{+}$ mice compared to $C k 2 \beta^{f l f l}$ mice (Fig. 3e). The activated follicle reduction appeared at the time of onset of sexual maturity (4 weeks) and displayed a similar decreased trend from week 4 to week 6 for primordial follicles in the ovaries of $\mathrm{Ck}_{2 \beta^{f l f f}} ; \mathrm{GCre}^{+}$mice (Fig. 3f). This phenotype resembles premature ovarian failure (POF) in humans.

The histological analysis indicated that absence of CK2 $\beta$ in oocytes caused follicular atresia and POF. To confirm these observations, we performed immunohistochemistry of the germ cell marker MVH on 3- and 8-week-old ovarian sections. As shown in Fig. 4a, in ovaries of $C k_{2} \beta^{f l / f l} ; \mathrm{GCre}^{+}$mice at 3 weeks of age, most follicles including primordial, primary, secondary, and antral follicles showed MVH-positive staining, suggesting that these follicles were healthy. However, at 8 weeks of age, there were few MVH-positive primordial or primary follicles scattering in the cortical region in ovaries of $\mathrm{Ck}^{2} \beta^{f l f f} ; \mathrm{GCre} e^{+}$mice, which was symptomatic of POF. TUNEL assay on ovarian sections showed that increased granulosa cell apoptosis occurred in ovaries of $C k 2 \beta^{f l f l} ; G C r e^{+}$mice at 4 weeks of age compared to ovaries in $C k 2 \beta^{f l f l}$ mice, which was caused by growing follicle atresia (Fig. 4b). The above data demonstrate that the accelerated demise of primordial follicles and defective survival of growing follicles may be responsible for infertility of $C k 2 \beta^{f l / f}$; $\mathrm{GCre}^{+}$female mice.

\section{Ck2 $\beta$ deletion causes PI3K/AKT signaling hypoactivation}

According to the above-mentioned research, $C k 2 \beta^{f l / f l}$; $\mathrm{GCre}^{+}$mice displayed defects in primordial follicle survival. Accumulating literature indicates that PI3K/AKT signaling plays a vital role in regulating the survival of primordial follicles during their long dormancy ${ }^{54-56}$. In view of the involvement of CK2 in the PI3K/AKT pathway at a cellular level, we first focus our attention on the PI3K/ AKT pathway. Accordingly, we performed immunoblotting analysis using ovaries from $C k 2 \beta^{f l / f l}$ and $C k 2 \beta^{f l / f l}$; $\mathrm{GCre}^{+}$mice at 2 weeks of age. It showed that the levels of phosphorylated AKT (S473 and S129) decreased slightly, whereas phosphorylated AKT (T308) was markedly reduced (Fig. 5a); when considering the elevated total level of AKT1/2/3 protein (Fig. 5a), the relative level of phosphorylated AKT (S473, T308, and S129) was decreased more obviously in CK2 $\beta$ mutant ovaries. PI3K/ AKT regulator PTEN was also detected and it showed decreased expression (Fig. 5a). Subsequently, the downstream of PI3K/AKT pathway was detected. We first examined the TSC2/mTOR signaling which was critical to oocyte survival. The results showed that the activity of mTOR/rpS6 signaling pathway was enhanced in mutant ovaries, as indicated by elevated levels of phosphorylated mTOR (S2448), phosphorylated S6K (T389), and phosphorylated rpS6 (Ser240/244) (Fig. 5b). However, the levels of phosphorylated TSC2 (S1387) displayed no difference between mutant and control ovaries (Fig. 5b). These results were inconsistent when considering that mTOR was negatively regulated by TSC2. The upregulated $\mathrm{mTOR} / \mathrm{S} 6 \mathrm{~K} / \mathrm{rpSK}$ signaling may result from feedback effects on defective follicle survival. Afterward, other AKT substrates contributing to cell survival were further detected. As the first reported AKT substrate which is important to cell survival, two isoforms of glycogen synthase kinase 3 (GSK3), GSK3 $\alpha$ and GSK3 $\beta$, were detected. The results showed that the level of GSK3 $\alpha$ expressed in ovaries was higher than GSK3 $\beta$ (Fig. 5c), and the expression levels of both phosphorylated GSK3 $\alpha / \beta$ (S21/ 9) and total GSK $3 \alpha / \beta$ protein displayed no variation in control and mutant mice (Fig. 5c). We next detected FOXO proteins which are also important cell survivalrelated AKT substrates. The examination of the levels of phosphorylated FOXO1 (T24)/FOXO3a (T32) found that they were significantly decreased (Fig. $5 \mathrm{c}$ ), while the levels of total FOXO1 protein did not show obvious changes (Fig. 5c).

\section{$C k 2 \beta$ depletion results in accumulated DNA damage in oocytes}

Double-strand breaks derived from unrepaired meiotic or environmental stress could result in oocyte elimination and female infertility through CHK2-dependent activation of $\mathrm{p} 53$ or $\mathrm{p} 63^{57}$. Considering that CK2 is involved in the 
a

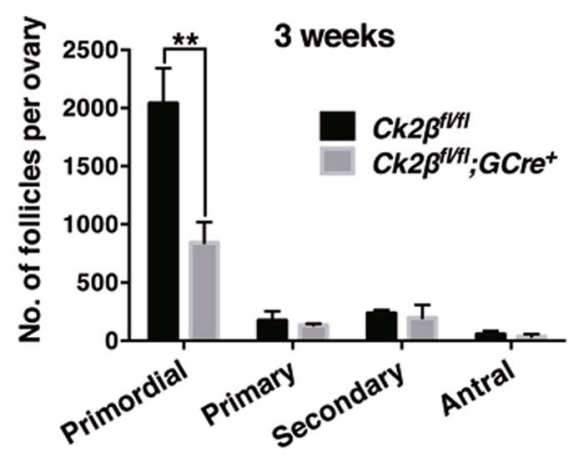

C

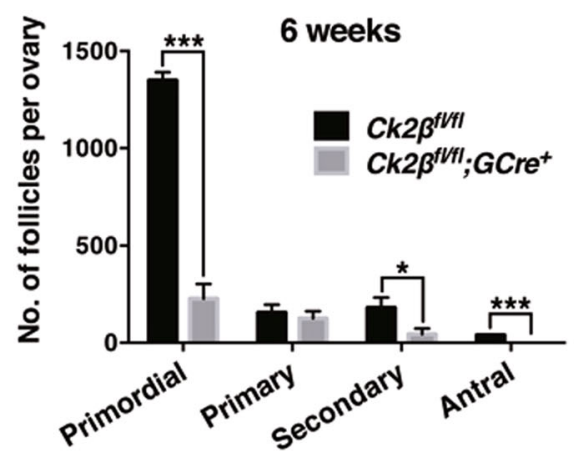

e

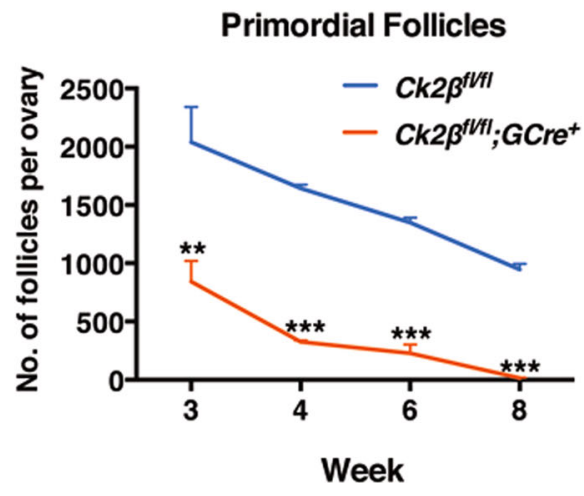

b

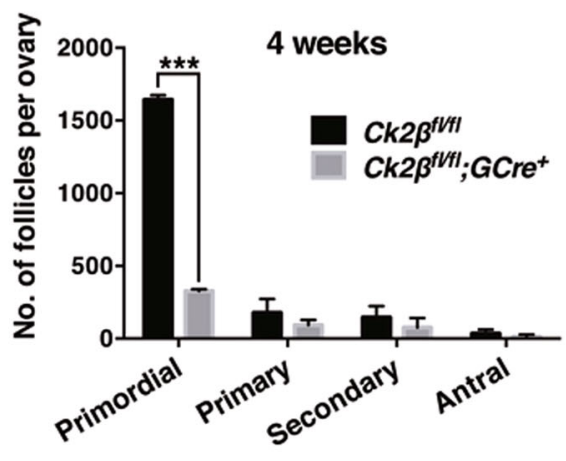

d

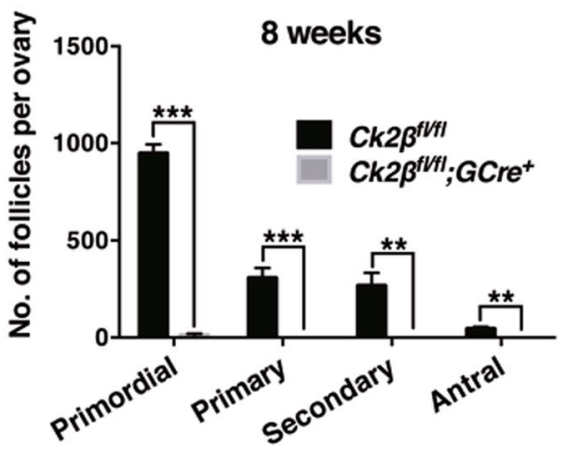

f

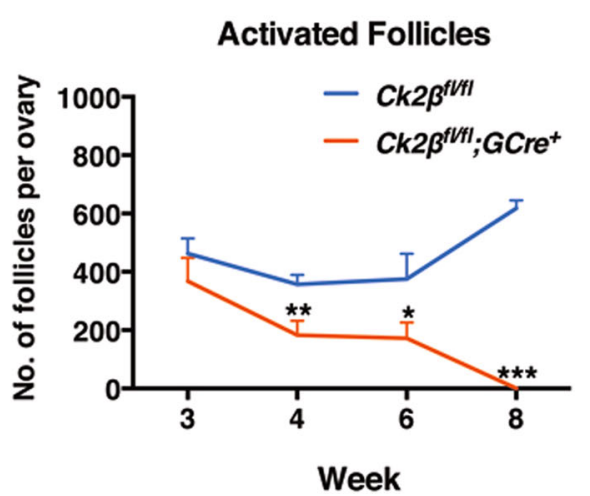

Fig. 3 Decreased number of primordial and activated follicles in $C k 2 \beta^{f / f} ; G C r e^{+}$mice. a-d Quantification of numbers of different types of follicles in ovaries at 3 weeks, 4 weeks, 6 weeks, and 8 weeks, respectively. Primordial, primary, secondary, and antral follicles were counted. For each time point, at least three mice of each genotype were used for analysis. Data are presented as the mean \pm SEM. $P<0.05\left(^{*}\right), 0.01\left(^{* *}\right)$ or $0.001\left(^{* * *}\right)$. e-f Quantification of numbers of primordial follicles (e) and activated follicles ( $\mathbf{f}$ ) in ovaries at 3 weeks, 4 weeks, 6 weeks, and 8 weeks, respectively. For each time point, at least three mice of each genotype were used for analysis. Data are presented as the mean \pm SEM. $P<0.05\left(^{(*)}, 0.01\left(^{* *}\right)\right.$ or $0.001\left(^{(* *}\right)$

DNA damage response pathway ${ }^{32,34-36}$, we wonder whether $C k 2 \beta^{-1-}$ oocyte depletion relates to this pathway. Thus, we first performed immunoblotting using ovary lysates from $C k 2 \beta^{f l f l}$ and $C k 2 \beta^{f l / f l} ; G C r e^{+}$mice at 2 weeks of age. As shown in Fig. 6a, the levels of phosphorylated CHK2 (T68) were slightly increased and $\gamma \mathrm{H} 2 \mathrm{AX}$ was significantly upregulated in ovaries of $C k 2 \beta^{f l f l}$;GCre ${ }^{+}$ mice, whereas the levels of p63 and phosphorylated p53
(S15) showed no difference in ovaries of $C k 2 \beta^{f l / f l}$ and $C k 2 \beta^{f l / f l} ; \mathrm{GCre}^{+}$mice. However, by 4 weeks of age, the level of p63 was downregulated while phosphorylated p53 (S15) was upregulated in ovaries of $C k 2 \beta^{f l f l}$;GCre ${ }^{+}$mice (Fig. 6b), consistent with the antagonizing relationship between p53 and p6357. Moreover, we confirmed our findings using immunofluorescence analysis. As indicated in Fig. 6c, the $\gamma \mathrm{H} 2 \mathrm{AX}$ signals in small oocytes from 


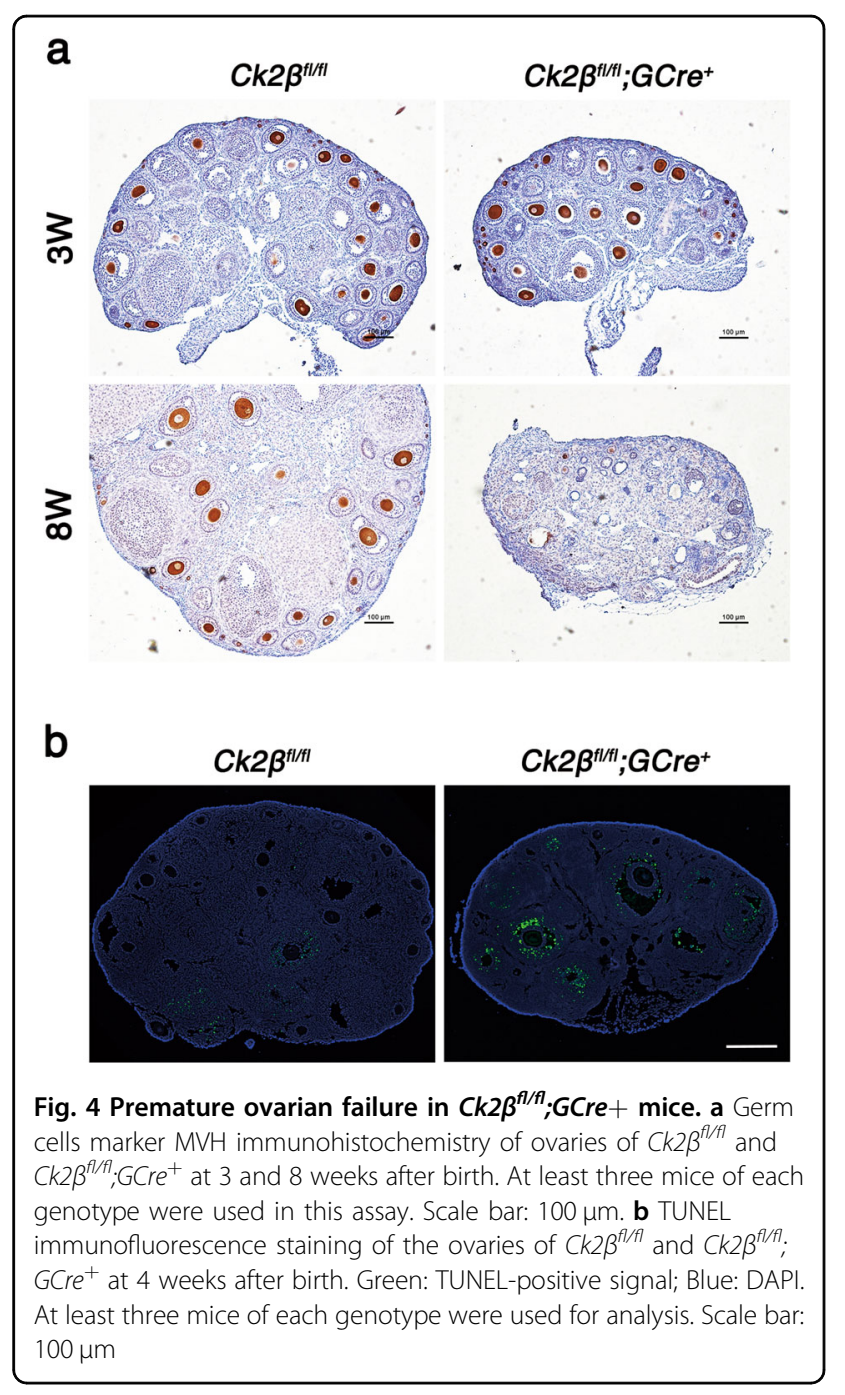

$C k 2 \beta^{f l f l} ; G C r e^{+}$mice at 2 weeks of age were remarkably enhanced. Taken together, these data suggest that CK2 $\beta$ depletion causes DSBs accumulation and failed activation of the DNA damage response pathway.

\section{Oocyte-specific deletion of CK2 $\beta$ causes a striking reduction in CK2 $a$ but not CK2 $\alpha^{\prime}$ expression}

To explore the forms of CK2 functions in the mouse ovary, immunoblotting was carried out to detect protein levels of CK $2 \alpha, C K 2 \alpha^{\prime}$, and CK2 $\beta$ in ovaries of $C k 2 \beta^{f l / f l}$ and $C k 2 \beta^{f l f f} ; G C r e^{+}$mice (Fig. 7). As expected, the level of CK2 $\beta$ protein was dramatically reduced in ovary extracts prepared from $C k 2 \beta^{f l f l} ; G C r e^{+}$mice compared with $C k 2 \beta^{f l f l}$ mice. The low level of CK2 $\beta$ protein that was detected in the ovary extracts collected from $C k 2 \beta^{f l / f l}$; $\mathrm{GCre}^{+}$mice likely came from granulosa cells in which CK2 $\beta$ was not deleted. Meanwhile, the level of CK2 $\alpha$ protein was significantly downregulated in ovaries of $C k 2 \beta^{f l / f l} ; G C r e^{+}$mice, while the levels of CK2 $\alpha^{\prime}$ protein in ovaries of $C k^{f f l f l} ; \mathrm{GCre}^{+}$mice showed no variation compared with $C k 2 \beta^{f l f l}$ mice. Immunoblotting analysis of phospho-CK2 substrate using ovaries from control and mutant mice found that CK2 activity was largely reduced (Fig. 7b). These data suggest that CK2 is presumably functioning in oocytes in the forms of $\alpha_{2} \beta_{2}$ and the reduced expression of $C K 2 \alpha$ protein in ovaries of $C k 2 \beta^{f l f f l}$; $\mathrm{GCre}^{+}$mice is probably due to degradation resulting from decreased stability of $C K 2 \alpha$ protein without CK2 $\beta$.

\section{Discussion}

In humans, the primordial germ cells (PGCs) migrate to gonadal ridges and are enclosed by pregranulosa cells to form primordial follicles. Most ovarian primordial follicles

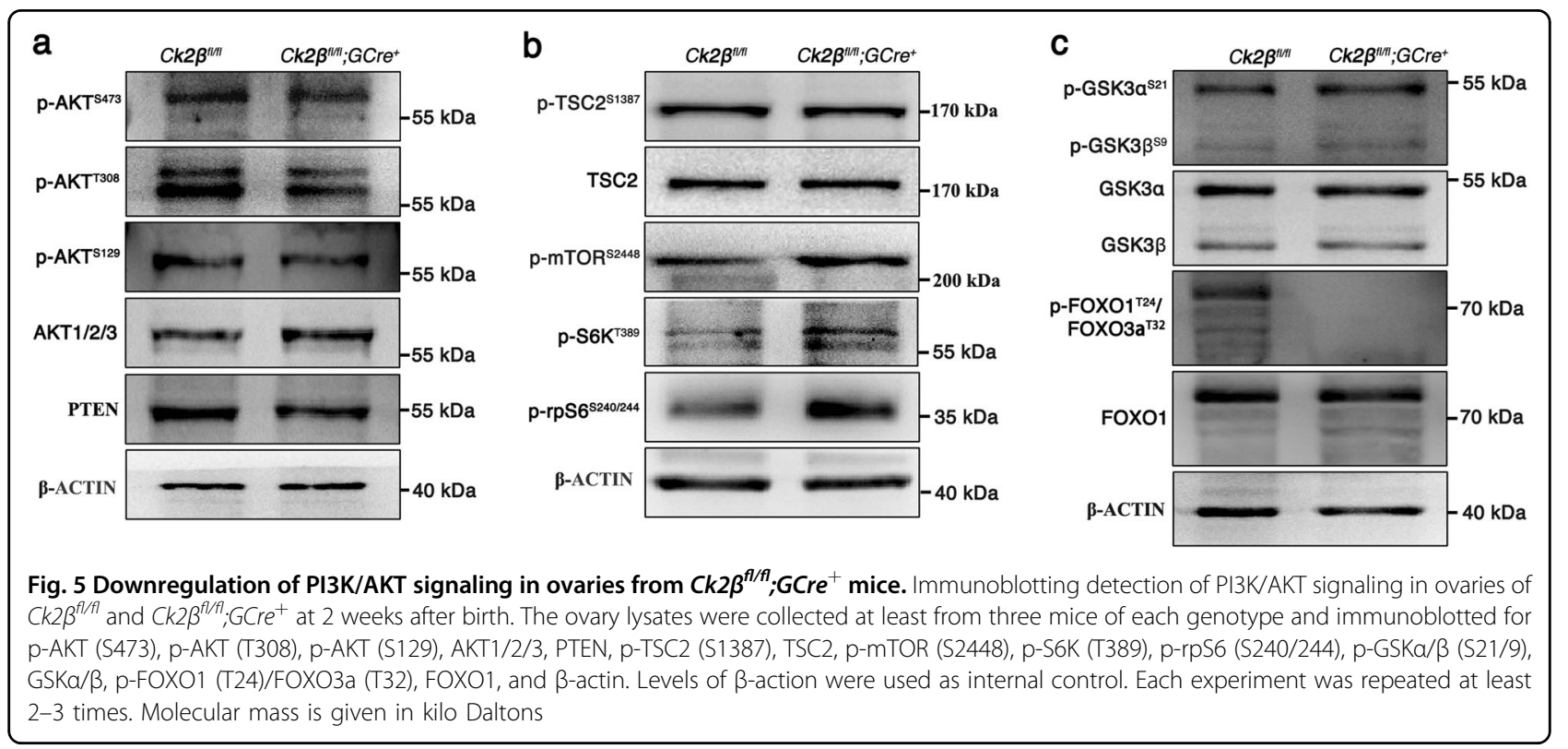



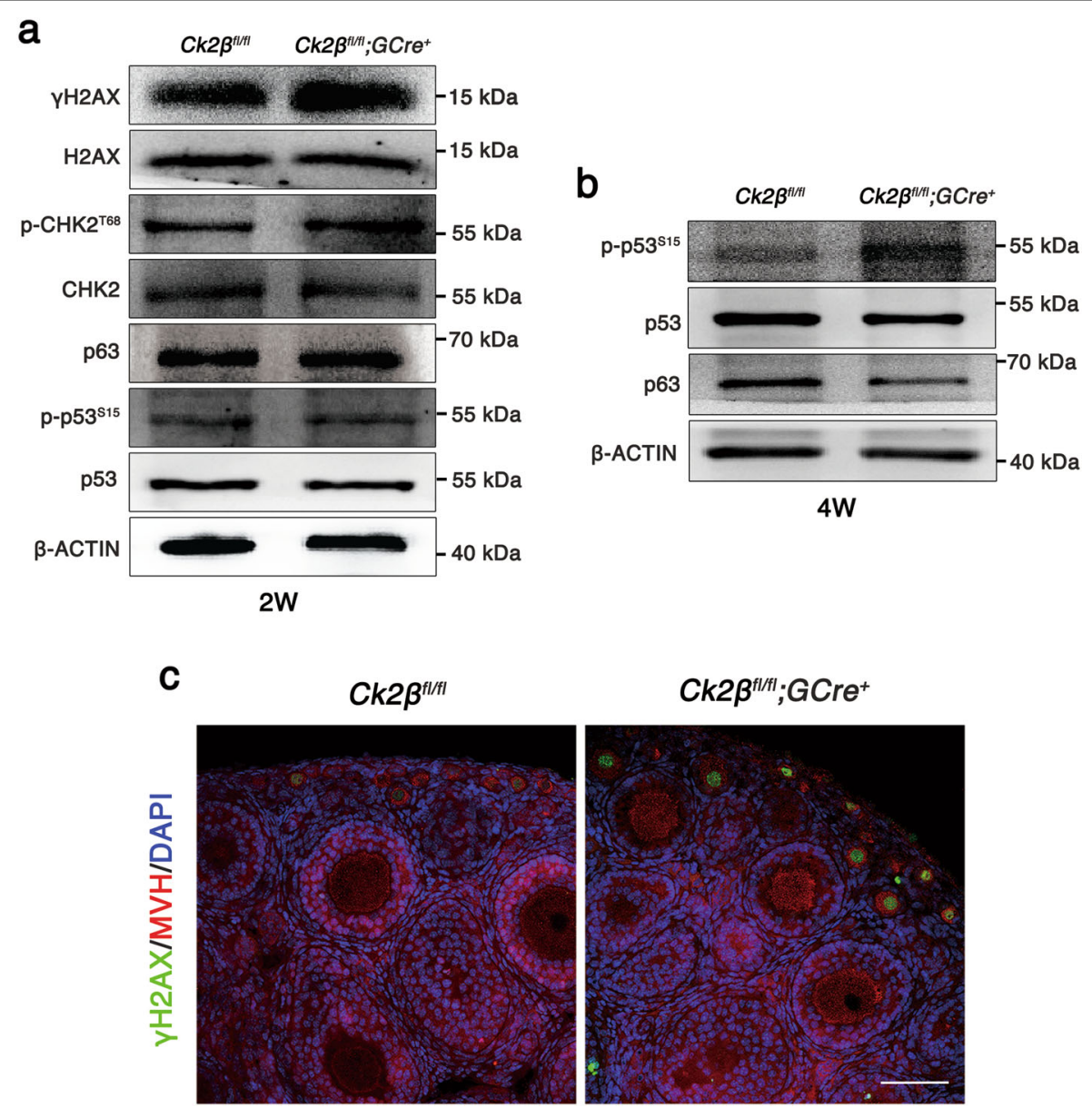

Fig. 6 Impaired follicle survival in $C k 2 \beta^{f / f} ; G C r e^{+}$mice involved in DNA damage response. a Immunoblotting analysis of DNA damage response signaling in ovaries of $C k_{2} \beta^{f / f l}$ and $C k_{2} \beta^{f / f} ; G C r e^{+}$mice at 2 weeks after birth. The ovary lysates were collected at least from three mice of each genotype and immunoblotted for $\gamma \mathrm{H} 2 \mathrm{AX}, \mathrm{H} 2 \mathrm{AX}$, p-CHK2 (T68), CHK2, p63, p-p53 (S15), p53 and $\beta$-actin. Level of $\beta$-actin was detected as internal control. Each experiment was repeated at least 2-3 times. Molecular mass is given in kilo Daltons. $\mathbf{b}$ Immunoblotting analysis of the expression of p53 and p63 in ovaries of $C k_{2} \beta^{f / / 7}$ and $C k 2 \beta^{f / f} ; G C r e^{+}$at 4 weeks after birth. The ovary lysates were obtained from at least three mice of each genotype and immunoblotted for p63, p-p53 (S15), p53 and $\beta$-actin. Level of $\beta$-actin was used as internal control. Each experiment was repeated at least three times. Molecular mass is given in kilo Daltons. c MVH and $\gamma \mathrm{H} 2 \mathrm{AX}$ immunofluorescent staining of 2-week-old ovarian sections from $C \mathrm{k} 2 \beta^{f / / f l}$ and $C \mathrm{~K} 2 \beta^{f / /}$ ${ }^{f l} ; G C r e^{+}$mice. Green: $\gamma H 2 A X$; Red: MVH; Blue: DAPI. At least three mice of each genotype were used in this assay. Scale bar: $50 \mu \mathrm{m}$

are maintained in a quiescent state, providing as a reserve for a woman's reproductive life ${ }^{58}$. Premature depletion of the ovarian reserve incurs cessation of ovarian function, resulting in $\mathrm{POF}^{59}$. Elucidating the mechanisms that control the dormancy and survival of primordial follicles is critical for understanding of ovarian biology. In this study, using Gdf9 promotor-driven Cre recombinase, we successfully deleted CK2 $\beta$ in oocytes from the primordial follicle stage, which facilitated investigation on the roles of CK $2 \beta$ in folliculogenesis. We found that CK2 $\beta$ mutant females showed defective follicular survival and sterility.

Morphological observation revealed that the ovary size of CK $2 \beta$ mutant mice started to decrease from 3 weeks after birth and eventually became reduced to about $1 / 4$ of that in control mice at 8 weeks, which was consistent with histological observations and follicle counts. At 3 weeks, most follicles looked healthy but the primordial follicles in ovaries of CK2 $\beta$ mutant mice were markedly reduced compared to control mice. Starting at 4 weeks, the ovaries of CK2 $\beta$ mutant mice showed increasing numbers of atretic follicles, which were eliminated quickly, resulting in the decrease of the number of activated follicles.

Previous researches reveal that PI3K signaling is critical to control the survival of primordial follicles, since suppressed or elevated PI3K/AKT signaling leads to premature depletion of follicles, causing $\mathrm{POF}^{54-56}$. In this study, we systematically analyze the PI3K/AKT signaling. Immunoblotting results showed that $C k 2 \beta$ depletion caused downregulation of phosphorylated AKT (S473, 


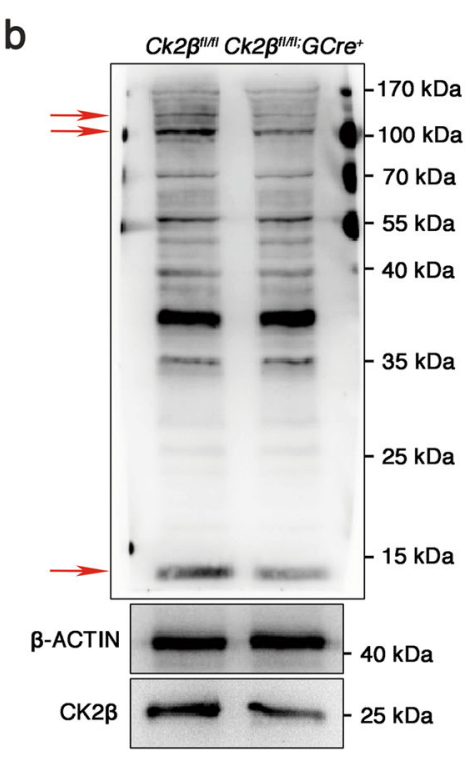

Fig. 7 Detection of expression of CK2 subunits and CK2 activity in $C k 2 \beta^{f / f} ; G C r e^{+}$mouse ovaries. a Immunoblotting detection of the expression of $\mathrm{CK} 2 \mathrm{a}$ and $\mathrm{CK} 2 \mathrm{a}^{\prime}$ in ovaries of $\mathrm{Ck} 2 \beta^{\mathrm{fl} / \mathrm{fl}}$ and $\mathrm{Ck} 2 \beta^{\mathrm{fl} / \mathrm{f}} ; \mathrm{GCr} e^{+}$at 2 weeks after birth. $\mathbf{b}$ Immunoblotting detection of CK2 activity in ovaries of $C k 2 \beta^{f / f}$ and $C k 2 \beta^{f / f} ; G C r e e^{+}$at 2 weeks after birth. The obviously altered bands were marked with red arrows. The ovary lysates were obtained from at least three mice of each genotype and immunoblotted for CK2a, CK2a, CK2 $\beta$, and phospho-CK2 substrate, $\beta$-actin. Level of $\beta$-actin was used as internal control. Each experiment was repeated at least three times. Molecular mass is given in kilo Daltons

T308, and S129). Previous studies find that CK2 can phosphorylate AKT/PKB at Ser129 and such phosphorylation of AKT prevents AKT Thr308 dephosphorylation and enhances the catalytic activity of $\mathrm{AKT} / \mathrm{PKB}^{24,30,37}$. Previous studies also show that CK2 can phosphorylate PTEN at several sites and such phosphorylation prevents PTEN degradation and inhibits its activity ${ }^{38-40}$. Consequently, deletion of CK2 $\beta$ causes low stability and high activity of PTEN, leading to reduced level of PTEN protein and downregulated AKT phosphorylation.

Studies of targets of AKT found that the activity of TSC2 was not changed but its downstream pathway $\mathrm{mTOR} / \mathrm{S} 6 \mathrm{~K} /$ rpSK signaling was significantly enhanced in CK2 $\beta$ mutant ovaries. These findings are in conflict with previous reports which suggest that elevated $\mathrm{mTOR} / \mathrm{S} 6 \mathrm{~K} / \mathrm{rpSK}$ signaling is responsible for oocyte growth and follicular activation and suppressed mTOR/S6K/rpSK signaling leads to loss of primordial follicles ${ }^{54,55}$. The upregulated mTOR/S6K/ rpSK signaling may result from feedback effects to defective follicle survival. Further studies of other targets of AKT found that the levels of phosphorylated GSK3 $\alpha / \beta$ (S21/9) were not changed. However, phosphorylated FOXO1 (T24)/FOXO3a (T32) were downregulated in CK2 $\beta$ mutant mice. CK2 $\beta$ deletion downregulates activated AKT, which in turn inhibits FOXO phosphorylation and keeps FOXO1 staying in nucleus ${ }^{60,61}$. Unphosphorylated FOXO proteins trigger expression of genes that are crucial for the induction of apoptosis, such as FASL and $\mathrm{BIM}^{62}$. From above results, CK2 $\beta$ regulates follicular survival at least partly via PI3K/AKT/FOXO pathway, although details remain to be elucidated.

The oocytes derived from primordial follicle are arrested at the diplotene stage of prophase of first meiotic division for months, even years, after birth depending on species. The oocytes at the diplotene stage have finished synapsis that relies on homologous recombination, a highfidelity DNA double-strand breaks (DSBs) repair process. Any homolog synapsis or DSB repair errors would prompt DNA damage checkpoints to eliminate defective meiotic oocytes, which is mediated by the CHK2-p53/p63 pathway $^{57,63}$. Considering the involvement of CK2 in the DNA damage response pathway in other species ${ }^{32,34-36}$, we then studied this pathway in CK2 $\beta$ mutant ovaries. In our study, oocyte-specific deletion of CK2 $\beta$ from the primordial follicle stage caused elevated $\gamma \mathrm{H} 2 \mathrm{AX}$ and phosphorylated CHK2 (T68) signals in ovaries and elevated $\gamma \mathrm{H} 2 \mathrm{AX}$ signals in small oocytes from mice at 2 weeks of age, indicating accumulated DSBs. By 4 weeks of age, the DNA damage response pathway was significantly elevated, indicated by the upregulated level of phosphorylated p53 (S15) in ovaries of $C k_{2} \beta^{l l f l} ; \mathrm{GCre} e^{+}$ mice. Accordingly, the follicular atresia at least early follicle atresia may be partly dependent on DNA damage response pathway.

In this study, as expected, the level of CK2 $\beta$ protein was significantly reduced in CK2 $\beta$ mutant ovaries compared to controls. However, the level of CK $2 \alpha$ also showed an obvious decrease despite of no difference in the levels of 
CK $2 \alpha$ ' in CK2 $\beta$ mutant ovaries and control ovaries. This is consistent with a previous report in which $\mathrm{CK} 2 \alpha^{-1-}$ females show normal fertility ${ }^{51}$. The above data reveal that CK2 presumably functions in oocytes in the forms of $\alpha_{2} \beta_{2}$, but since $\mathrm{CK} 2 \alpha^{-1-}$ embryos die at the embryonic stage ${ }^{50}$, oocyte-specific knockdown of CK2 $\alpha$ is necessary to validate the hypothesis.

In summary, we identified CK2 $\beta$ as a key protein safeguarding mouse follicle survival and fertility. Our data provide new insights into occurrence, diagnosis, and treatment of POF.

\section{Materials and methods \\ Mice}

Mice lacking $C k 2 \beta$ in oocytes (referred to as $C k 2 \beta^{f l f f}$; $\mathrm{GCre}^{+}$) were obtained by crossing previously reported $C k 2 \beta^{f l f l}$ mice $^{53}$ with Gdf9-Cre (C57BL6 background) mice $^{64}$. The $C k 2 \beta^{f l / f l}$ female mice were used as control group. DNA extraction from mouse tail was used to genotype $C k 2 \beta^{\Lambda}, C k 2 \beta^{f l}$, and Gdf9-Cre alleles, respectively. The primer pair for $C k 2 \beta^{\Delta}$ allele was forward: $5^{\prime}$-GAGGGCATAGTAGATATGAATCTG-3' and reverse: 5'-GGATAGCAAACTCTCTGAG-3'. The primer pair for $C k 2 \beta^{f l}$ allele was forward: 5'-ATGAGTAGCTCTGAGGAGGTG$3^{\prime}$ and reverse: $5^{\prime}$-GGATAGCAAACTCTCTGAG-3'. The primer pair for Gdf9-Cre allele was forward: AGGCATGCTTGAGGTCTGAT, and reverse: CACAGTCAGCAGGTTGGAGA. All animal operations were approved by the Animal Research Committee principles of the Institute of Zoology, Chinese Academy of Sciences.

\section{Antibodies}

Rabbit monoclonal anti-CK2 $\beta$ antibody (AJ1128b; ABGENT); mouse monoclonal anti- $\beta$-actin antibody (sc47778; Santa Cruz); mouse monoclonal anti-MVH antibody (ab27591; abcam); rabbit monoclonal anti-p-Akt (S473) antibody (4046; Cell Signaling Technology, Inc.); rabbit monoclonal anti-p-Akt (T308) (13038; Cell Signaling Technology, Inc.); rabbit monoclonal anti-p-Akt (S129) (ab133458; abcam); rabbit monoclonal anti-AKT1/ 2/3 antibody (ab32505; abcam); rabbit monoclonal antiPTEN antibody (9559; Cell Signaling Technology, Inc.); rabbit polyclonal anti-p-TSC2 (S1387) antibody (5584; Cell Signaling Technology, Inc.); rabbit monoclonal antiTSC2 antibody (4308; Cell Signaling Technology, Inc.); rabbit monoclonal anti-p-mTOR (S2448) antibody (5536; Cell Signaling Technology, Inc.); rabbit monoclonal antip-S6K (T389) antibody (9234; Cell Signaling Technology, Inc.); rabbit monoclonal anti-p-rpS6 (S240/244) antibody (5364; Cell Signaling Technology, Inc.); rabbit polyclonal anti-GSK3 $\alpha / \beta$ (S21/9) antibody (9331; Cell Signaling Technology, Inc.); rabbit monoclonal anti-GSK3 $\alpha / \beta$ antibody (5676; Cell Signaling Technology, Inc.); rabbit polyclonal anti-p-FOXO1 (T24)/FOXO3a (T32) antibody
(9464; Cell Signaling Technology, Inc.); rabbit monoclonal anti-FOXO1 antibody (2880; Cell Signaling Technology, Inc.); rabbit monoclonal anti- $\gamma \mathrm{H} 2 \mathrm{AX}$ antibody (9718; Cell Signaling Technology, Inc.); rabbit monoclonal antiH2AX antibody (7631; Cell Signaling Technology, Inc.); rabbit polyclonal anti-p-CHK2 (T68) antibody (BS4043; Bioworld Technology, Inc.); rabbit polyclonal anti-CHK2 antibody (BS6791; Bioworld Technology, Inc.); rabbit monoclonal anti-p-p53 (S15) (12571; Cell Signaling Technology, Inc.); rabbit polyclonal anti-p53 antibody (BS3156; Bioworld Technology, Inc.); rabbit monoclonal anti-p63 (ab124762; abcam); mouse monoclonal antiCK2 $\alpha$ antibody (ab70774; abcam); rabbit polyclonal antiCK2 $\alpha^{\prime}$ antibody (BS6571; Bioworld Technology, Inc.); rabbit monoclonal anti-phospho-CK2 substrate $[(\mathrm{pS} / \mathrm{pT})$ DXE] (8738; Cell Signaling Technology, Inc.); secondary antibodies were purchased from Zhongshan Golden Bridge Biotechnology Co, Ltd (Beijing).

\section{Immunoblotting}

Ovary extracts were prepared using a homogenizer in RIPA buffer supplemented with protease and phosphatase inhibitor cocktail (Roche Diagnostics). After transient ultrasound, the ovary lysates were incubated on ice for 30 min and then centrifuged at $4{ }^{\circ} \mathrm{C}, 12,000 \mathrm{rpm}$ for $20 \mathrm{~min}$. The supernatant was transferred to a new tube and equal volume loading buffer was added. After being boiled at 95 ${ }^{\circ} \mathrm{C}$ for $10 \mathrm{~min}$, the protein lysates were used for immunoblotting analysis. Immunoblotting was performed as described previously ${ }^{65}$. Briefly, the separated proteins in SDS-PAGE were electrically transferred to a polyvinylidene fluoride membrane. After incubation with primary and secondary antibodies, the membranes were scanned with Bio-Rad ChemiDoc XRS+.

\section{Hematoxylin and eosin staining and quantification of ovarian follicles}

Ovaries were dissected from $C k 2 \beta^{f l / f l}$ and $C k 2 \beta^{f l f l}$; $\mathrm{GCre}^{+}$mice immediately after killing. The ovaries were fixed in $4 \%$ formaldehyde overnight at $4{ }^{\circ} \mathrm{C}$, dehydrated in an ethanol series and embedded in paraffin. Paraffinembedded ovaries were cut into sections of 8 - $\mu \mathrm{m}$ thickness and mounted on glass slides. After $48^{\circ} \mathrm{C}$ overnight drying, the sections were deparaffinized in xylene, hydrated by a graded alcohol series and stained with hematoxylin and eosin for histological analyses. Ovarian primordial, primary, secondary, and antral follicles were counted in every fifth section of an ovary. Quantification of ovarian follicles was performed as previously reported $^{66,67}$. In each section, follicles that contained oocytes with clearly visible nuclei were scored and the cumulative number of follicles were multiplied by a correction factor of 5 to represent the estimated number of total follicles in an ovary. 


\section{Immunohistochemistry and immunofluorescence}

Ovaries used for immunostaining were fixed in $4 \%$ paraformaldehyde ( $\mathrm{pH}$ 7.4) overnight at $4{ }^{\circ} \mathrm{C}$, dehydrated, and embedded in paraffin. Paraffin-embedded ovaries were cut into sections of $5-\mu \mathrm{m}$ thickness. Then, the sections were deparaffinized, immersed in sodium citrate buffer ( $\mathrm{pH}$ 6.0), and heated for $15 \mathrm{~min}$ in a microwave for antigen retrieval. After blocking with 5\% donkey serum albumin, sections were incubated with primary antibodies at $4{ }^{\circ} \mathrm{C}$ overnight. For immunohistochemistry, the sections were treated with $3 \% \mathrm{H}_{2} \mathrm{O}_{2}$ to eliminate internal peroxidase activity and incubated with an appropriate horseradish peroxidase (HRP)-conjugated secondary antibody. Finally, the signal of primary antibody was detected by the Vectastain $A B C$ kit (Vector Laboratories, CA, USA) and the sections were counterstained with hematoxylin. Images were captured using a Nikon DS-Ri1 CCD camera. For immunofluorescence, the sections were incubated with an appropriate FITC-conjugated secondary antibody. The nuclei were stained with DAPI. Images were captured using a laser scanning confocal microscope (Zeiss 780 META).

\section{TUNEL assay}

TUNEL assay was carried out in accordance to the DeadEnd ${ }^{\mathrm{TM}}$ Fluorometric TUNEL System (Promega BioSciences, Madison, WI, USA). Images were captured using a laser scanning confocal microscope (Zeiss 780 META).

\section{Breeding assay}

In the breeding assay, 6-8 week-old $C k 2 \beta^{f l / f l}$ and $C k 2 \beta^{f l}$ ${ }^{f l} ; \mathrm{GCre}^{+}$female mice were mated to 8-week-old C57BL/6J wild-type male mice with known fertility. At least five mice of each genotype were used in this assay. For 6 months, the cages were monitored daily for recording the number of pups and litter size.

\section{Statistical analysis}

All experiments were performed at least three times. Paired two-tailed Student's $t$ test was used for statistical analysis. Data were presented as mean \pm SEM and $P<0.05$ $(*), 0.01(* *)$, or $0.001\left(^{* * *}\right)$ was considered statistically significant.

\section{Acknowledgements}

We appreciate and acknowledge Shiwen Li and Xili Zhu for their technical assistance. We thank all members of the Sun lab for their help and discussion. This work was supported by the National Key Research and Development Program of China (2016YFC1000600 and 2017YFC1001500), National Natural Science foundation of China (No. 31671559 and No. 31501204), the Research Team of Female Reproductive Health and Fertility Preservation in the Reproductive Medicine of Peking University Third Hospital (SZSM201612065) and Project for Medical Discipline Advancement of Health and Family Planning Commission of Shenzhen Municipality (SZXJ2017003).

\section{Author details}

'Department of Reproductive Medicine, Peking University Shenzhen Hospital, 518036 Shenzhen, Guangdong, China. ${ }^{2}$ State Key Laboratory of Stem Cell and
Reproductive Biology, Institute of Zoology, Chinese Academy of Sciences, 100101 Beijing, China. ${ }^{3}$ University of Chinese Academy of Sciences, 100101 Beijing, China. ${ }^{4}$ Center for Reproductive Medicine, Nanjing Drum Tower Hospital, The Affiliated Hospital of Nanjing University Medical School, 210008 Nanjing, China. ${ }^{5}$ Department of Veterinary Pathobiology, University of Missouri, Columbia, MO 65211, USA. ${ }^{6}$ INSERM U1036, Institute de Recherches en Technologies et Sciences pour le Vivant/Biologie du Cancer et de I'Infection, Commissariat à l'Énergie Atomique et aux Énerigies Alternatives Grenoble, Grenoble, France. ${ }^{7}$ KinaseDetect, Krusaa, Denmark

\section{Conflict of interest}

The authors declare that they have no conflict of interest.

\section{Publisher's note}

Springer Nature remains neutral with regard to jurisdictional claims in published maps and institutional affiliations.

Supplementary Information accompanies this paper at (https://doi.org/ 10.1038/s41419-018-0505-1).

Received: 27 October 2017 Revised: 12 March 2018 Accepted: 14 March 2018

Published online: 03 May 2018

References

1. Conway, G. S. Premature ovarian failure. Br. Med. Bull. 56, 643-649 (2000).

2. Coulam, C. B., Adamson, S. C. \& Annegers, J. F. Incidence of premature ovarian failure. Obstet. Gynecol. 67, 604-606 (1986).

3. Conway, G. S., Payne, N. N., Webb, J., Murray, A. \& Jacobs, P. A. Fragile X premutation screening in women with premature ovarian failure. Hum. Reprod. 13, 1184-1187 (1998).

4. Marozzi, A. et al. Association between idiopathic premature ovarian failure and fragile X premutation. Hum. Reprod. 15, 197-202 (2000).

5. Laml, T., Preyer, O., Umek, W., Hengstschlager, M. \& Hanzal, H. Genetic disorders in premature ovarian failure. Hum. Reprod. Update 8, 483-491 (2002).

6. Tuohy, V. K. \& Altuntas, C. Z. Autoimmunity and premature ovarian failure. Curr. Opin. Obstet. Gynecol. 19, 366-369 (2007).

7. Wilson, C. Autoimmunity: autoimmune Addison disease and premature ovarian failure. Nat. Rev. Endocrinol. 7, 498 (2011).

8. Perez-Andujar, A., Newhauser, W. D., Taddei, P. J., Mahajan, A. \& Howell, R. M. The predicted relative risk of premature ovarian failure for three radiotherapy modalities in a girl receiving craniospinal irradiation. Phys. Med. Biol. 58, 3107-3123 (2013)

9. Long, J. P., Wan, F., Zhang, F., Zhou, J. \& Don, L. F. DTC chemotherapy regimen is associated with higher incidence of premature ovarian failure in women of reproductive age with breast cancer. Eur. Rev. Med. Pharmacol. Sci. 20, 1087-1092 (2016).

10. Wittenberger, M. D. et al. The FMR1 premutation and reproduction. Fertil. Steril. 87, 456-465 (2007)

11. Murray, A., Webb, J., Dennis, N., Conway, G. \& Morton, N. Microdeletions in FMR2 may be a significant cause of premature ovarian failure. J. Med. Genet. 36, 767-770 (1999).

12. Di Pasquale, E., Beck-Peccoz, P. \& Persani, L. Hypergonadotropic ovarian failure associated with an inherited mutation of human bone morphogenetic protein-15 (BMP15) gene. Am. J. Hum. Genet. 75, 106-111 (2004).

13. Dixit, $\mathrm{H}$. et al. Missense mutations in the BMP15 gene are associated with ovarian failure. Hum. Genet. 119, 408-415 (2006).

14. Tiotiu, D. et al. Variants of the BMP15 gene in a cohort of patients with premature ovarian failure. Hum. Reprod. 25, 1581-1587 (2010).

15. Harris, S. E. et al. Identification of novel mutations in FOXL2 associated with premature ovarian failure. Mol. Hum. Reprod. 8, 729-733 (2002).

16. Laissue, P. et al. Functional evidence implicating FOXL2 in non-syndromic premature ovarian failure and in the regulation of the transcription factor OSR2. J. Med. Genet. 46, 455-457 (2009).

17. Aittomaki, K. et al. Mutation in the follicle-stimulating hormone receptor gene causes hereditary hypergonadotropic ovarian failure. Cell 82, 959-968 (1995).

18. Latronico, A. C. et al. Brief report: testicular and ovarian resistance to luteinizing hormone caused by inactivating mutations of the luteinizing hormonereceptor gene. N. Engl. J. Med. 334, 507-512 (1996). 
19. Shelling, A. N. et al. Inhibin: a candidate gene for premature ovarian failure. Hum. Reprod. 15, 2644-2649 (2000)

20. Chand, A. L., Harrison, C. A. \& Shelling, A. N. Inhibin and premature ovarian failure. Hum. Reprod. Update 16, 39-50 (2010).

21. Litchfield, D. W. Protein kinase CK2: structure, regulation and role in cellular decisions of life and death. Biochem. J. 369, 1-15 (2003).

22. Guerra, B., Issinger, O. G. \& Wang, J. Y. Modulation of human checkpoint kinase Chk1 by the regulatory beta-subunit of protein kinase CK2. Oncogene 22, 4933-4942 (2003)

23. Yde, C. W., Olsen, B. B., Meek, D., Watanabe, N. \& Guerra, B. The regulatory betasubunit of protein kinase CK2 regulates cell-cycle progression at the onset of mitosis. Oncogene 27, 4986-4997 (2008).

24. Di Maira, G. et al. Protein kinase CK2 phosphorylates and upregulates Akt/PKB. Cell Death Differ. 12, 668-677 (2005).

25. Guerra, B. Protein kinase CK2 subunits are positive regulators of AKT kinase. Int. J. Oncol. 28, 685-693 (2006).

26. Shehata, M. et al. Reconstitution of PTEN activity by CK2 inhibitors and interference with the PI3-K/Akt cascade counteract the antiapoptotic effect of human stromal cells in chronic lymphocytic leukemia. Blood 116, 2513-2521 (2010).

27. Song, C. et al. Targeting casein kinase II restores Ikaros tumor suppressor activity and demonstrates therapeutic efficacy in high-risk leukemia. Blood 126, 1813-1822 (2015).

28. Wang, S. \& Jones, K. A. CK2 controls the recruitment of Wnt regulators to target genes in vivo. Curr. Biol. 16, 2239-2244 (2006).

29. Gao, Y. \& Wang, H. Y. Casein kinase 2 is activated and essential for Wnt/betacatenin signaling. J. Biol. Chem. 281, 18394-18400 (2006).

30. Ponce, D. P. et al. CK2 functionally interacts with AKT/PKB to promote the beta-catenin-dependent expression of survivin and enhance cell survival. Mol. Cell. Biochem. 356, 127-132 (2011).

31. Ponce, D. P. et al. Phosphorylation of AKT/PKB by CK2 is necessary for the AKTdependent up-regulation of beta-catenin transcriptional activity. J. Cell Physiol. 226, 1953-1959 (2011).

32. Ghavidel, A. \& Schultz, M. C. TATA binding protein-associated CK2 transduces DNA damage signals to the RNA polymerase III transcriptional machinery. Cell 106, 575-584 (2001)

33. Loizou, J. I. et al. The protein kinase CK2 facilitates repair of chromosomal DNA single-strand breaks. Cell 117, 17-28 (2004).

34. St-Denis, N. A. \& Litchfield, D. W. Protein kinase CK2 in health and disease: from birth to death: the role of protein kinase CK2 in the regulation of cell proliferation and survival. Cell. Mol. Life Sci. 66, 1817-1829 (2009).

35. Olsen, B. B., Wang, S. Y., Svenstrup, T. H., Chen, B. P. \& Guerra, B. Protein kinase CK2 localizes to sites of DNA double-strand break regulating the cellular response to DNA damage. BMC Mol. Biol. 13, 7 (2012).

36. Rabalski, A. J., Gyenis, L. \& Litchfield, D. W. Molecular pathways: emergence of protein kinase CK2 (CSNK2) as a potential target to inhibit survival and DNA damage response and repair pathways in cancer cells. Clin. Cancer Res. 22, 2840-2847 (2016).

37. Di Maira, G., Brustolon, F., Pinna, L. A. \& Ruzzene, M. Dephosphorylation and inactivation of Akt/PKB is counteracted by protein kinase CK2 in HEK 293T cells. Cell. Mol. Life Sci. 66, 3363-3373 (2009).

38. Torres, J. \& Pulido, R. The tumor suppressor PTEN is phosphorylated by the protein kinase CK2 at its C terminus - implications for PTEN stability to proteasome-mediated degradation. J. Biol. Chem. 276, 993-998 (2001).

39. Miller, S. J., Lou, D. Y., Seldin, D. C., Lane, W. S. \& Neel, B. G. Direct identification of PTEN phosphorylation sites. FEBS Lett. 528, 145-153 (2002).

40. Silva, A. et al. Regulation of PTEN by CK2 and Notch1 in primary T-cell acute lymphoblastic leukemia: rationale for combined use of CK2- and gammasecretase inhibitors. Haematologica 95, 674-678 (2010).

41. Kapoor, M. \& Lozano, G. Functional activation of p53 via phosphorylation following DNA damage by UV but not gamma radiation. Proc. Natl Acad. Sci. USA 95, 2834-2837 (1998).

42. Keller, D. M. et al. A DNA damage-induced p53 serine 392 kinase complex contains CK2, hSpt16, and SSRP1. Mol. Cell 7, 283-292 (2001).
43. Gotz, C., Kartarius, S., Scholtes, P., Nastainczyk, W. \& Montenarh, M. Identification of a CK2 phosphorylation site in mdm2. Eur. J. Biochem. 266, 493-501 (1999).

44. Allende-Vega, N., Dias, S., Milne, D. \& Meek, D. Phosphorylation of the acidic domain of Mdm2 by protein kinase CK2. Mol. Cell. Biochem. 274, 85-90 (2005).

45. Gotz, C., Wagner, P., Issinger, O. G. \& Montenarh, M. p21WAF1/CIP1 interacts with protein kinase CK2. Oncogene 13, 391-398 (1996).

46. Romero-Oliva, F. \& Allende, J. E. Proteinp21(WAF1/CIP1) is phosphorylated by protein kinase CK2 in vitro and interacts with the amino terminal end of the CK2 beta subunit. J. Cell. Biochem. 81, 445-452 (2001).

47. Tapia, J. C., Bolanos-Garcia, V. M., Sayed, M., Allende, C. C. \& Allende, J. E. Cell cycle regulatory protein p27KIP1 is a substrate and interacts with the protein kinase CK2. J. Cell. Biochem. 91, 865-879 (2004).

48. Bjorling-Poulsen, $\mathrm{M}$. et al. The 'regulatory' beta-subunit of protein kinase CK2 negatively influences p53-mediated allosteric effects on Chk2 activation. Oncogene 24, 6194-6200 (2005)

49. O'Brien, K. A., Lemke, S. J., Cocke, K. S., Rao, R. N. \& Beckmann, R. P. Casein kinase 2 binds to and phosphorylates BRCA1. Biochem. Biophys. Res. Commun. 260, 658-664 (1999).

50. Lou, D. Y. et al. The alpha catalytic subunit of protein kinase CK2 is required for mouse embryonic development. Mol. Cell. Biol. 28, 131-139 (2008).

51. Xu, X., Toselli, P. A., Russell, L. D. \& Seldin, D. C. Globozoospermia in mice lacking the casein kinase II alpha' catalytic subunit. Nat. Genet. 23, 118-121 (1999).

52. Escalier, D., Silvius, D. \& Xu, X. Spermatogenesis of mice lacking CK2alpha': failure of germ cell survival and characteristic modifications of the spermatid nucleus. Mol. Reprod. Dev. 66, 190-201 (2003).

53. Buchou, T. et al. Disruption of the regulatory beta subunit of protein kinase CK2 in mice leads to a cell-autonomous defect and early embryonic lethality. Mol. Cell. Biol. 23, 908-915 (2003).

54. Reddy, P. et al. Oocyte-specific deletion of Pten causes premature activation of the primordial follicle pool. Science 319, 611-613 (2008).

55. Reddy, P. et al. PDK1 signaling in oocytes controls reproductive aging and lifespan by manipulating the survival of primordial follicles. Hum. Mol. Genet. 18, 2813-2824 (2009).

56. Zheng, W., Nagaraju, G., Liu, Z. \& Liu, K. Functional roles of the phosphatidylinositol 3-kinases (PI3Ks) signaling in the mammalian ovary. Mol. Cell. Endocrinol. 356, 24-30 (2012).

57. Bolcun-Filas, E., Rinaldi, V. D., White, M. E. \& Schimenti, J. C. Reversal of female infertility by Chk2 ablation reveals the oocyte DNA damage checkpoin pathway. Science 343, 533-536 (2014).

58. McGee, E. A. \& Hsueh, A. J. Initial and cyclic recruitment of ovarian follicles. Endocr. Rev. 21, 200-214 (2000).

59. De Vos, M., Devroey, P. \& Fauser, B. C. Primary ovarian insufficiency. Lancet 376, 911-921 (2010).

60. Brunet, A. et al. Akt promotes cell survival by phosphorylating and inhibiting a Forkhead transcription factor. Cell 96, 857-868 (1999).

61. Kops, G. J. et al. Direct control of the Forkhead transcription factor AFX by protein kinase B. Nature 398, 630-634 (1999).

62. van der Vos, K. E. \& Coffer, P. J. The extending network of FOXO transcriptional target genes. Antioxid. Redox Signal. 14, 579-592 (2011).

63. Di Giacomo, M. et al. Distinct DNA-damage-dependent and -independent responses drive the loss of oocytes in recombination-defective mouse mutants. Proc. Natl Acad. Sci. USA 102, 737-742 (2005).

64. Lan, Z. J., Xu, X. \& Cooney, A. J. Differential oocyte-specific expression of Cre recombinase activity in GDF-9-iCre, Zp3cre, and Msx2Cre transgenic mice. Biol. Reprod. 71, 1469-1474 (2004).

65. Qi, S. T. et al. Overexpression of SETbeta, a protein localizing to centromeres, causes precocious separation of chromatids during the first meiosis of mouse oocytes. J. Cell Sci. 126, 1595-1603 (2013).

66. Pedersen, T. \& Peters, H. Proposal for a classification of oocytes and follicles in the mouse ovary. J. Reprod. Fertil. 17, 555-557 (1968).

67. Morita, Y., Perez, G. I., Maravei, D. V., Tilly, K. I. \& Tilly, J. L. Targeted expression of $\mathrm{BCl}-2$ in mouse oocytes inhibits ovarian follicle atresia and prevents spontaneous and chemotherapy-induced oocyte apoptosis in vitro. Mol. Endocrinol. 13, 841-850 (1999). 